\title{
ANALISIS FAKTOR - FAKTOR YANG MEMPENGARUHI KEPUTUSAN PEMBELIAN PRODUK FASTFOOD KFC DI KOTA SORONG (Studi Kasus Mega Mall Kota Sorong)
}

\author{
${ }^{1 *}$ Putri Sari Asih, ${ }^{2}$ Rais Dera Pua Rawi, ${ }^{3}$ Agilistiya Rahayu \\ Universitas Muhammadiyah Sorong, Papua Barat, Indonesia \\ *putrisariasih25@gmail.com
}

\begin{abstract}
Abstrak
Banyak faktor-faktor yang menjadi dasar seseorang konsumen sebelum melakukan pemilihan atau membeli suatu produk fastfood. Mulai dari faktor budaya, sub-budaya, faktor sosial dan faktor pribadi. Hal inilah yang menjadi dasar bagi setiap produsen dalam memasarkan produk mereka dan untuk mengetahui apa yang terjadi di lapangan. Tujuan penelitian ini dilakukan untuk mengetahui sejauh mana faktor sosial dan faktor pribadi mempengaruhi kepetusan pembelian KFC di Kota Sorong. Metode penelitian yang digunakan ialah analisis regresi linier berganda dengan menggunakan uji validitas, reliabilitas, asumsi klasik, uji F, dan uji t. Data yang digunakan ialah data primer dan data sekunder. Penelitian ini menggunakan 50 responden yang di ambil menggunakan insidental sampling. Hasil penelitian ini menunjukkan analisis regresi linier berganda dan uji $\mathrm{F}$ terdapat pengaruh yang positif dan signifikan antara faktor sosial dan faktor pribadi terhadap keputusan pembelian konsumen pada KFC di Kota Sorong. Dan dari dua variabel yang signifikan tersebut, variabel faktor sosial mempunyai pengaruh yang lebih besar atau dominan terhadap keputusan pembelian konsumen.
\end{abstract}

Kata Kunci: Faktor Sosial, Faktor Pribadi, Keputusan Pembelian Konsumen

\section{Abstract}

Many factors become the basis of a consumer before making a selection or buying a fast food product. Starting from cultural factors, sub-culture, social factors and personal factors. This is the basis for every producer in marketing their products and to find out what is happening in the field. The purpose of this study was to determine the extent to which social factors and personal factors influence the decision to purchase KFC in Sorong City. The research method used is multiple linear regression analysis using validity, reliability, classical assumptions, F test, and t test. The data used are primary data and secondary data. This study uses 50 respondents who were taken using incidental sampling. The results of this study indicate multiple linear regression analysis and $F$ test there is a positive and significant influence between social factors and personal factors on consumer purchasing decisions at KFC in Sorong City. And of the two significant variables, social factor variables have a greater or dominant influence on consumer purchasing decision.

Keywords: Social Factors, Personal Factors, Consumer Purchasing Decisions

\section{PENDAHULUAN}

Di Indonesia merupakan sala satu Negara yang menempati posisi urutan ke-4 setelah China, India, Amerika dalam jumlah kepadatan penduduk yang berjumlah $266,927,712$ jiwa. Perkembangan pada zaman modern ini kesibukan mulai terjadi di semua kalagan usia yang menyebabkan berbagai alternatif untuk penunjang keseharian. Salah satu alternative yang digunakan oleh semua kalangan manusia yaitu memilih untuk makan makanan cepat saji (fastfood) yang sekarang sudah menjadi fenomena makanan yang cukup potensial dan diakui keberadaannya oleh masyarakat. Dengan demikian mayoritas masyarakat penganut agama Islam maka kehalalan suatu produk fastfood juga menjadi dasar dalam menarik konsumen.

Khususnya di Kota Sorong, fenomena makanan cepat saji ini juga banyak dinikmati oleh semua kalangan. Para produsen pun menyiapkan strategi pemasaran yang begitu unik yang dapat disesuaikan dengan konsumen seperti apa 
yang dirasakan konsumen sebelum dan sesudah membeli produk.

Banyak faktor-faktor yang menjadi dasar seseorang konsumen sebelum melakukan pemilihan atau membeli suatu produk fastfood. Mulai dari faktor budaya, sub-budaya, faktor sosial dan faktor pribadi. Hal inilah yang menjadi dasar bagi setiap produsen dalam memasarkan produk mereka. Mengetahui apa yang terjadi di lapangan.

Keputusan Pembelian menurut Kotler (2002) adalah tindakan dari konsumen untuk mau membeli atau tidak terhadap produk. Dari berbagai faktor yang mempengaruhi konsumen dalam melakukan pembelian suatu produk atau jasa, biasanya konsumen selalu mempertimbangkan kualitas, harga dan produk sudah yang sudah dikenal oleh masyarakat.

Berdasarkan latar belakang di atas maka penulis tertarik untuk melakukan penelitian dalam bentuk skripsi dengan judul "Analisis Faktor - Faktor Yang Mempengaruhi Keputusan Pembelian Pada Produk Fastfood Kfc Di Kota Sorong".

\section{TINJAUAN PUSTAKA}

\section{Pemasaran}

\begin{tabular}{|c|}
\hline $\begin{array}{l}\text { Menurut Kotler }(2000: 9) \\
\text { mengatakan bahwa pemasaran } \\
\text { merupakan suatu proses sosial yang } \\
\text { mana didalamnya individu dan } \\
\text { kelompok mendapatkan apa yang } \\
\text { mereka inginkan dan butuhkan dengan } \\
\text { cara menciptakan, menawarkan dan } \\
\text { secara bebas mempertukarkan produk }\end{array}$ \\
\hline
\end{tabular}

2. Manajemen Pemasaran

$$
\text { Menurut Kotler }
$$
mengemukakan bahwa manajemen pemasaran merupakan suatu proses perencanaan dan pelaksanaan pemikiran, penetapan harga, promosi serta penyaluran gagasan, barang dan jasa untuk menciptakan pertukaran yang memenuhi sasaran-sasaran individu dan organisasi.

\section{Faktor- Faktor Yang Mempengaruhi Keputusan Pembelian Konsumen}

Menurut Nugroho (2013:10) mengemukakan bahwa ada beberapa faktor yang mempengaruhi keputusan pembelian konsumen, diantaranya yaitu

\section{Faktor Sosial}

Menurut Rudito (2008) mengatakan bahwa faktor sosial merupakan segala sesuatu yang dipakai sebagai acuan dalam berinteraksi antar manusia dalam konteks masyarakat atau komuniti. Kelompok acuan, Keluarga, dan Peran dan status social

\section{Faktor Pribadi}

Menurut Lamb (2001) mengatakan bahwa faktor pribadi merupakan suatu cara dalam mengumpulkan dan mengelompokkan kekonsistenan reaksi seorang individu terhadap situasi yang sedang terjadi. Faktor pribadi yang memberikan kontribusi terhadap perilaku konsumen terdiri dari: Usia dan tahap siklus hidup, Pekerjaan, Keadaan ekonomi, Gaya hidup, dan Kepribadian dan konsep diri

\section{Keputusan Pembelian}

Menurut Kotler (2002) keputusan pembelian merupakan tindakan dari konsumen untuk mau membeli atau tidak terhadap produk. Dari berbagai faktor yang mempengaruhi konsumen dalam melakukan pembelian suatu produk atau jasa, biasanya konsumen selalu mempertimbangkan kualitas, harga dan produk sudah yang sudah dikenal oleh masyarakat.

Sebelum konsumen memutuskan untuk membeli, biasanya konsumen melalui beberapa tahap terlebih dahulu yaitu:

a. Pengenalan masalah.

b. Pencarian informasi.

c. Evaluasi alternatif.

d. Keputusan membeli.

e. Perilaku sesudah pembelian

f. Kepuasan sesudah pembelian

g. Tindakan - tindakan sesudah pembelian 


\section{METODE}

Penelitian ini dilaksanakan di masyakarak umum Kota Sorong Papua Barat. Waktu Penelitian ini dilaksanakan selama 8 (delapan) bulan yang dimulai dari bulan September 2018 - Desember 2018.

Populasi dalam penelitian populasinya adalah seluruh konsumen yang datang atau pernah membeli produk KFC di Kota Sorong berjumlah 50 Responden, teknik pengambilan sampel menggunakan teknik sampling. Dengan teknik pengambilan data yaitu dengan observasi, wawancara pribadi dan kuesioner.

\section{HASIL DAN PEMBAHASAN}

1. Pembahasan Hasil Penelitian

Hasil dari analisis data diatas membuktikan bawa hipotesis dari penelitian, yaitu sebagai berikut :

\section{a. Hipotesis pertama}

Uji F digunakan untuk membuktikan apakah Faktor sosial dan faktor pribadi secara simultan berpengaruh terhadap keputusan pembelian konsumen pada KFC di Kota Sorong. Kriteria pengujian :

Jika $\mathrm{F}$ hitung $>\mathrm{F}_{\text {tabel, }}$ maka $\mathrm{H}_{\mathrm{O}}$ ditolak dan $\mathrm{H}_{\mathrm{A}}$ diterima. Hal ini menunjukkan bahwa variabel faktor sosial $\left(X_{1}\right)$ dan faktor pribadi $\left(X_{2}\right)$ secara simultan berpengaruh terhadap keputusan pembelian konsumen.

Jika $\mathrm{F}_{\text {hitung }} \leq \mathrm{F}_{\text {tabel, }}$ maka $\mathrm{H}_{\mathrm{O}}$ ditolak dan $\mathrm{H}_{\mathrm{A}}$ diterima. Hal ini menunjukkan bahwa variabel faktor sosial $\left(X_{1}\right)$ dan faktor pribadi $\left(X_{2}\right)$ secara simultan berpengaruh terhadap keputusan pembelian konsumen.

Pengujian secara berganda menghasilkan $F_{\text {hitung }}=19,126>F_{\text {tabel }}=$ 3,19 maka keputusan pengujian adalah $\mathrm{H}_{\mathrm{O}}$ ditolak dan $\mathrm{H}_{\mathrm{A}}$ diterima. Hal ini menunjukkan bahwa variabel faktor sosial dan faktor pribadi secara simultan berpengaruh positif terhadap keputusan pembelian konsumen pada KFC di Kota Sorong.
Sedangkan nilai koefisien determinasi $R^{2}$ sebesar 0,449 memiliki pengertian bahwa faktor sosial dan fakto pribadi secara bersama - sama mampu menjelaskan variasi keputusan pembelian konsumen sebesar $44,9 \%$ selebihnya 55,1\% yang diteliti dalam penelitian ini.

\section{b. Hipotesis Kedua}

Uji $\mathrm{T}$ digunakan untuk membuktikan Pengaruh faktor sosial dan faktor pribadi terhadap keputusan pembelian konsumen pada KFC di Kota Sorong.

1) Variabel Faktor Sosial

Antara faktor sosial dan keputusan dan keputusan pembelian KFC di Kota Sorong mempunyai pengaruh, ini ditunjukkan dengan besar koefisien regresi yaitu sebesar 1,184 satuan, berarti apabila terdapat kenaikan sebesar 1 satuan untuk variabel faktor sosial maka keputusan pembelian konsumen sebesar 1,184 satuan, demikian pula sebaliknya. Telah dilakukan uji statistik dengan uji $t$ memberikan hasil yang signifikan nilai $t_{\text {hitung }}$ sebesar 4,160 lebih besar dari nilai $t_{\text {tabel }}$ 1.675. Berarti Faktor sosial sangat berpengaruh terhadap keputusan pembelian konsumen.

2) Variabel Faktor Pribadi

Antara Faktor Pribadi dan keputusan dan keputusan pembelian KFC di Kota Sorong mempunyai pengaruh, ini ditunjukkan dengan besar koefisien regresi yaitu sebesar 0,144 satuan, berarti apabila terdapat kenaikan sebesar 1 satuan untuk variabel faktor pribadi maka keputusan pembelian konsumen sebesar 0,144 satuan, demikian pula sebaliknya. Berdasarkan hasil analisis regresi diperoleh nilai $t_{\text {hitung }}$ sebesar 0,859 lebih kecil dari dar nilai $t_{\text {tabel }}$ 1.675. Maka dapat disimpulkan bahwa "Faktor 
pribadi $\left(\mathrm{X}_{2}\right)$ tidak berpengaruh signifikan terhadap Keputusan Pembelian Konsumen (Y).

Berdasarkan perhitungan uji $\mathrm{T}$, terlihat bahwa variabel faktor sosial memiliki koefisien regresi yang paling besar, yakni sebesar 1,184 , sehingga variabel faktor sosial yang paling dominan berpengaruh terhadap keputusan pembelian KFC di Kota Sorong. Ini dikarenakan variabel faktor sosial memberikan informasi kepada konsumen.

\section{PENUTUP}

\section{Kesimpulan}

Seteleh melakukan analisis data dan pembahasan tentang "Analisis Faktor Faktor Yang Mempengaruhi Keputusan Pembelian Pada Produk Fastfood KFC di Kota Sorong", maka dapat mengambil kesimpulan sebagai berikut :

1. Dua faktor yang diajukan untuk dianalisis dalam faktor - faktor yang mempengaruhi keputusan pembelian ialah Faktor Sosial $\left(X_{1}\right)$ dan Faktor Pribadi $\left(\mathrm{X}_{2}\right)$.

2. Dari hasil analisis regresi linier berganda dan uji $\mathrm{F}$ terdapat pengaruh yang positif dan signifikan antara Faktor Sosial $\left(\mathrm{X}_{1}\right)$ dan Faktor Pribadi $\left(X_{2}\right)$ terhadap keputusan pembelian konsumen pada KFC di Kota Sorong.

3. Dari hasil uji $\mathrm{T}$, menunjukkan bahwa variabel Faktor Sosial $\left(X_{1}\right)$ dan Faktor Pribadi $\left(X_{2}\right)$ memiliki pengaruh yang signifikan terhadap keputusan pembelian pada KFC di Kota Sorong.

4. Dari dua variabel yang signifikan tersebut, variabel Faktor Sosial $\left(X_{1}\right)$ mempunyai pengaruh yang lebih besar atau dominan terhadap keputusan pembelian konsumen pada KFC di Kota Sorong.

\section{Saran}

Berdasarkan hasil pembahasan dalam penelitian ini, maka penulis memberikan beberapa saran sebagai berikut:
1. Meskipun analisa faktor-faktor keputusan pembelian yang dilakukan oleh Perusahaan KFC dapat dikategorikan berhasil dalam mengenalkan produknya terhadap konsumen. Namun, pihak perusahaan senantiasa mengembangkan lagi kualitas produk dan pelayanan pemasaran yang baik terhadap konsumen.

2. Memberikan masukan kepada pihak perusahaan untuk tetap menjaga dan mengembangkan variabel penting yang tidak diteliti dalam penelitian ini yang dapat mempengaruhi konsumen dalam membuat keputusan.

3. Melalui penelitian ini variabel faktor sosial dan faktor pribadi memiliki pengaruh yang paling dominan dan hal tersebut meniscayakan perlunya pengembangan yang menyeluruh terhadap variabel dan analisa faktorfaktor yang akan dijalankan guna mencapai pemenuhan kebutuhan konsumen sebagaimana yang diharapkan

4. Dalam penelitian ini hanya menggunakan dua variabel yaitu faktor sosial dan faktor pribadi, maka penulis mengharapkan untuk kedepannya skripsi ini dapat diteruskan dan dikembangkan menjadi lebih lengkap oleh peneliti selanjutnya.

\section{DAFTAR PUSTAKA}

Erlangga, H. (2021). Effect Of Digital Marketing And Social Media On Purchase Intention Of Smes Food Products. Turkish Journal of Computer and Mathematics Education (TURCOMAT), 12(3), 3672-3678.

Erlangga, H., Sifatu, W. O., Wibisono, D., Siagian, A. O., Salam, R., \& Mas'adi, M. (2020). Pharmaceutical Business Competition in Indonesia: A Review. Systematic Reviews in Pharmacy, 11(10), 617-623.

Fauzie D., Yulianto E., \& Sunarti. (2016) Pengaruh Faktor Psikologis Konsumen Terhadap Keputusan Pembelian (Survei Pada Konsumen KFC Cabang Mall Olympic Garden Malang). Malang. 
Haque, M. G., Munawaroh, M., Sunarsi, D., \& Baharuddin, A. (2021). Competitive Advantage in Cost Leadership and Differentiation of SMEs "Bakoel Zee" Marketing Strategy in BSD. PINISI Discretion Review, 4(2), 277-284.

Kasmad, K., Mustakim, M., \& Sunarsi, D. (2020). Increasing Community School Interest Through Service Quality, Prices and Promotion in Vocational High Schools. Journal of Educational Science and Technology (EST), 6(2).

Kotler, Philip. (2002). Manajemen Pemasaran: Jilid 1. Edisi Milenium. Jakarta: Prehallindo.

Laksana, F. (2008). Manajemen Pemasaran: Pendekatan Praktis. Yogyakarta: Graha Ilmu.

Leon Schiffman (2004) Perilaku Konsumen Edisi Tujuh. Jakarta: Indeks.

Monintja R. Y., Mandey S. \& Soegoto A. S. (2015) Analisis Merek, Promosi dan Harga Pengaruhnya Terhadap Keputusan Pembelian Di Gelael Swalayan Manado. Manado.

Nugroho, J. S. (2003). Perilaku Konsumen: Konsep Dan Implikasi Untuk Strategi Dan Penelitian Pemasaran. Jakarta: Kencana.

Nurjaya, N., Affandi, A., Erlangga, H., Sunarsi, D., \& Jasmani, J. (2021). The Effect of Product Promotion and Innovation Activities on Marketing Performance in Middle Small Micro Enterprises in Cianjur. Budapest International Research and Critics
Institute (BIRCI-Journal): Humanities and Social Sciences, 4(1), 528-540.

Purwanti, Y. (2021). The Influence Of Digital Marketing \& Innovasion On The School Performance. Turkish Journal of Computer and Mathematics Education (TURCOMAT), 12(7), 118-127.

Rasyid, N., \& Rawi, R. D. P. (2018). Pengaruh Bauran Pemasaran Terhadap Penjualan Pada Pt. Nestle Indofood Citarasa Indonesia Di Makassar. Sentralisasi, 7(2), 11-27.

Rawi, R. D. P., \& Lewenussa, R. (2019). Pengaruh Karakteristik Dan Kinerja Generation Young (Gen Y) Terhadap Ekspektasi Peluang Bisnis (Studi Kasus Di PT. Adira Group Kota Sorong). Gorontalo Management Research, 2(2), 80-89.

Ridayani N. K. G. (2015) Analisis Pengaruh Perilaku Konsumen Terhadap Keputusan Pembelian Koran Kompas.

Sugiyono. (2016). Metode Penelitian: Pendekatan Kuantitatif, Kualitatif, Kombinasi (Mixed Methods), Penelitian Tindakan (Action Research) dan Penelitian Evaluasi . Bandung: Alfabeta.

Suryani, Tatik. (2008). Perilaku Konsumen: Implikasi Pada Strategi Pemasaran. Yogyakarta: Graha Ilmu.

Wangsi, M. M., \& Rawi, R. D. P. (2018). Perlindungan Konsumen Dalam Pelabelan Produk Menurut Ekonomi Islam. Sentralisasi, 7(1), 1-9. 